OSOBA | WOLA

Filozofia Chrześcijańska • Tom 10, Poznań 2013

Uniwersytet im. Adama Mickiewicza w Poznaniu • Wydziat Teologiczny

PRZEMYSLAW STRZYŻYŃSKI

Department of Theology, University of Adam Mickiewicz

Poznań, Poland.

\title{
Benjamin Libet's experiment and its critique between 2000-2012
}

Eksperyment Benjamina Libeta i jego krytyka w latach 2000-2012

\section{INTRODUCTION}

This paper presents an outline of discussion surrounding the Libet experiment, based on the review of subject literature from 2000-2012. The first part presents the experiment itself as well as Libet's own conclusions. The following part describes the resulting critical reaction, whereas the final part is devoted to presenting conclusions that suggest themselves after analysing this debate.

The paper is by no means a comprehensive treatment of the topic. We focus on the articles presented in the Journal Citation Reports and Oxford Handbook of Free Will ${ }^{1}$.

We aim not only to review the critical response to the experiment and its conclusions, but also to answer the question whether the results of the Libet experiment justify the thesis that the so-called free will has a physiological basis.

We shall also touch upon the following areas: assumptions related to the nature of free will, and the compatibilism-incompatibilism controversy. We shall not, however, discuss these in much detail.

\section{LIBET'S EXPERIMENT AND HIS CONCLUSIONS}

The following description is based on Libet's articles published between 1983 and 2006. His primary aim was to show that the intention of making

${ }^{1}$ Oxford handbook of free will, ed. R. Kane, New York, 2002; idem (ed.), Oxford handbook of free will, New York 2011. 
a movement is temporarily primary to its physiological components, such as the activation of brain areas responsible for making movements. The actual results he obtained proved to be completely opposite ${ }^{2}$.

The volunteers were asked to bend their wrists or fingers when they start feeling an urge, want, or intention. Simultaneously EEG analysis was performed with active electrodes on the scalp at the midline-vertex $(\mathrm{Cz})$, over the premotor and motor cortex (ca. 4, 6 Brodman's area). Also, the changes in tension of muscles responsible for arm movements were monitored using EMG. The participants were presented with a modified clock, so that they were able to determine, remember and report the time (W) when the urge, want or intention of making a move occurred. Brain activity was assessed using the so-called readiness potentials (RP; German: Bereitschaftspotential, BP). In another, similar experiment, Libet asked the participants to refrain from making a move despite the occurring urge, intention, etc. He described this act of refraining as the „,veto control”.

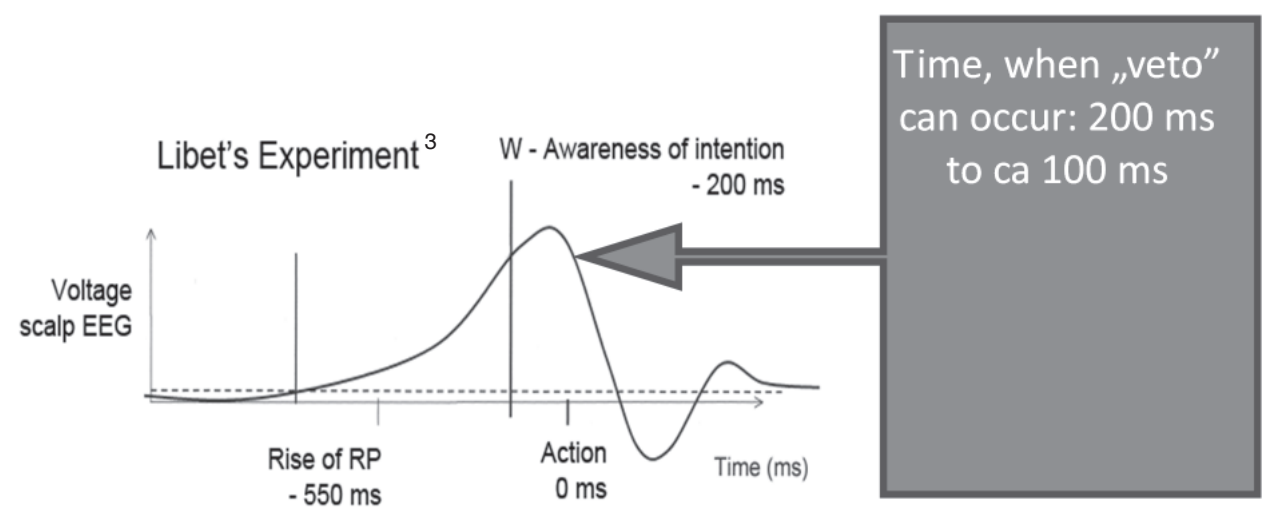

Libet's approach was to measure time backwards, hence the negative values, from the moment of making a move (Action $0 \mathrm{~ms}$, see Figure above). The oftenrepeated attempts proved that the brain activity, recorded as RP, precedes with ca. 350 milliseconds (ms) the intention of making the move (W - Awareness of intention) as recorded in memory. Whereas, the ability to refrain from making a move, after a related intention occurred, could be recorded for up to $100 \mathrm{~ms}$ before the time $0^{4}$.

In what follows we present Libet's conclusions. Despite the fact that they were presented in publications decades apart, their content remains very similar.

\footnotetext{
${ }^{2}$ J. Bremer, Wprowadzenie do filozofii umysłu, Kraków 2010, footnote 72, p. 184.

${ }^{3}$ www.rupertsheldrake.wordrpess.com [dostęp 07.01.2013]

${ }^{4}$ B. Libet, Do we have free will?, in: R. Kane (ed.) Oxford handbook of free will, New York 2002 , p. 551 .
} 
Describing his first results, Libet states: „the brain 'decides' to initiate or, at least, prepare to initiate [certain actions] before there is any reportable subjective awareness that such a decision has taken place"5. We also note, after Schlosser, that the word „decides" was used in inverted commas ${ }^{6}$. This means that Libet is cautious about the hypothesis that consciousness and intentions are determined by neuronal processes.

When it comes to the problem of free will, he notes: "if the 'act now' process is initiated unconsciously, then conscious free will is not doing it" " Libet also notes that:

Freely voluntary acts are preceded by a specific electrical change in the brain (the "readiness potential", RP) that begins $550 \mathrm{msec}$. before the act. Human subjects became aware of intention to act 350-400 msec. after $R P$ starts, but $200 \mathrm{msec}$. before the motor act. The volitional process is therefore initiated unconsciously. But the conscious function could still control the outcome; it can veto the act. Free will is therefore not excluded. These findings put constrains on views of how free will may operate; it would not initiate a voluntary act but it could control performance of the act. The findings also affect views of guilt and responsibility. But the deeper question still remains: Are freely voluntary acts subject to macro-deterministic laws or cant hey appear without such constraints, nondetermined by natural laws and "truly free"? [...] The first of these options would make free will illusory. The conscious feeling of exerting one's will would then be regarded as an epiphenomenon, simply a byproduct of the brain's activities but with no causal powers of its own' .

As he points out:

[...] free choices or acts are unpredictable, even if they should be completely determined. The "uncertainty principle" of Heisenberg precludes our having a complete knowledge of the underlying molecular activities. ...And, in chaos theory, a random event may shift the behavior of a whole system, in a way that was not predictable. However, even if events are not predictable in practice, they might nevertheless accord with natural laws and therefore be determined ${ }^{9}$.

He notes however that the assumption that the subjective consciousness is determined by the laws of nature ,is a speculative belief, not a scientifically proven

\footnotetext{
${ }^{5} \mathrm{~B}$. Libet, Unconscious cerebral initiative and the role of conscious will in voluntary action, "Behavioral and Brain Science", 8, 1985, p. 536, after: M.E. Schlosser, Free will and the unconscious precursors of choice, "Philosophical Psychology", vol. 25, no. 3, 2012, p. 367.

${ }^{6}$ M.E. Schlosser, Free will and the unconscious ..., op.cit., p. 370.

${ }^{7}$ B. Libet, Consciousness, free action and the brain, "Journal of Consciousness Studies", no. 8, 2001, p, 62, after: A.R. Mele, Free will: Theories, analysis, and data, in: Does consciousness cause behavior?, ed. S. Pockett, W.P. Banks, S. Gallagher, Cambridge 2006, p. 190.

${ }^{8}$ B. Libet, Do we have free will?, ..., op.cit., p. 551, 561.

${ }^{9}$ Ibidem, p. 561-562.
} 
proposition" ${ }^{10}$. Similarly, there is no supporting evidence for indeterminism. It is also an unproven speculative belief, however a theory , ,[...] that simply interprets the phenomenon of free will as illusory and denies the validity of this phenomenal fact is less attractive than a theory that accepts or accommodates the phenomenal fact"11. For this reason, Libet is leaning towards an indeterministic interpretation of his experiments:

[...] why not adopt the view that we do have free will (until some real contradictory evidence may appear, if it ever does)? Such a view would at least allow us to proceed in a way that accepts and accommodates our own deep feeling that we do have free will. We would not need to view ourselves as machines that act in a manner completely controlled by the known physical laws ${ }^{12}$.

Hence, Libet's conclusions can be described as moderate. Moreover, they were interpreted as such by many researchers. According to Pockett, Banks and Gallagher, the experiment result indicates that "conscious awareness came before the actual movement, but after the start of the brain activity leading up to it", however Libet himself does not conclude that consciousness is completely epiphenomenal or acausal ${ }^{13}$.

According to Libet, his experimental results can influence not only the notion of will but also of moral responsibility. He indicates that defining will as 'refraining from actions' is consistent with the approach presented in the Decalogue. Since "The role of conscious free will would be, then, not to initiate a voluntary act, but rather to control occurrences of the act" this is consistent with some ethical and religious requirements; the Decalogue for example consists mainly of prohibitions ${ }^{14}$. On the other hand the ,religious system that castigates an individual for simply having a mental intention or impulse to do something unacceptable, even this is not acted out, world create physiologically insurmountable moral and psychological difficulty" ${ }^{\prime 1}$. According to Libet, the view that the thoughts and desires themselves can be considered sinful or constitute a fault, makes everyone a guilty person ${ }^{16}$.

\footnotetext{
${ }^{10}$ Ibidem, p. 562.

${ }^{11}$ Ibidem, p. 563.

12 Ibidem, p. 563.

${ }^{13}$ S. Pockett, W.P. Banks, S. Gallagher, Introduction, in: Does consciousness..., op.cit., p. 1.

${ }^{14}$ B. Libet, Do we have free will?, ..., op.cit., p. 560.

${ }^{15}$ Ibidem, p. 561.

${ }^{16}$ Ibidem.
} 


\section{CRITIQUE OF LIBET'S EXPERIMENT}

By a critique we mean both the attempts to support and to reject the experiment results and Libet's conclusions. Following Bremer and Schlosser, the critique has been divided into two parts: methodological arguments and critique of Libet's conclusions (interpretation) ${ }^{17}$.

\section{Methodological arguments}

A. The problem with the research tools

According to Pockett, the research using EEG and MEG are characterised by a high temporal resolution but an insufficient spatial one. It is hard to pinpoint exactly the brain area initialising the RP. In contrast, the methods based on the blood flow are of high spatial but low temporal resolutions. What would be required is an invasive, intracortical, method but for ethical reasons, such methods are rarely used.

According to Pockett, some researches think that RP probably comes from the supplementary motor area/MII (SMA) ${ }^{18}$. However, after investigating the subcortical structures, Rektor suggests that the cranial RP signals also contain an admixture coming from the subcortical centres. Rektor does not state however, which subcortical areas were active $200 \mathrm{~ms}$ before the movement ${ }^{19}$.

The Shibashaki group observed RP in the midcranial region but, similarly to Rektor, were unable to locate the sources $200 \mathrm{~ms}$ prior to movement ${ }^{20}$.

This suggests serious difficulties in determining the exact brain regions from which RP originates. If it was shown that RP does not come directly from the regions responsible for movements and that there are other regions involved, this would complicate slightly Libet's reasoning. If we assumed that the brain areas responsible for movement initiate movement and at the same time we concluded that these were not activated first, but instead were activated as a result of the activation of deeper regions (for the time being not connected to movement), it

${ }^{17}$ J. Bremer, Wprowadzenie ..., op.cit., p. 186-189; M.E. Schlosser, Free will and..., op.cit., p. 367.

${ }^{18}$ S. Pockett, The Neuroscience of movement, in: Does consciousness..., op.cit., p. 17.

${ }^{19}$ I. Rektor, Scalp-recorded Bereitschaftspotential is the result of the activity of cortical and subcortical generators - a hypothesis, "Clinical Neurophysiology" 113, 2002, p. 1998-2005, after: S. Pockett, The Neuroscience of movement, op.cit., p. 17.

${ }^{20}$ Satow T. et al., Distinct cortical areas for motor preparation and execution in human identified by Bereitschaftspotential recording and EcoG-EMG coherence analysis, "Clinical Neurophysiology" 114, 2003, p. 1259-1264, after: S. Pockett, The Neuroscience of movement, ..., op.cit., p. 17. 
would change: firstly the knowledge on brain regions responsible for movement; secondly it would show that the movement regions themselves are being activated by other brain regions. This in turn would suggest a question regarding the exact relation, in terms of Libet's interpretation, of the activation of brain regions before an intention occurred with the conclusion about the brain initiation of not only the movement but the intention as well. Since, if these unknown regions activated the regions responsible for movement, then, following the principle that if something is a cause, it has to precede its effect, and then such regions could be considered responsible for initiating both movement and intention. There are, however, other interpretations possible. For example: a. the activation of the brain regions responsible for movement and intention is initiated in another, common, brain area, but takes place separately; b. the movement is initiated at the borderline between brain and mind in time that is earlier than the activation of the motor cortex and the feeling of intention.

\section{B. The problems related to determining time $\mathrm{W}$}

The most commonly raised methodological objection is that the approach to measure the time of occurrence of conscious will was not sufficiently precise. Broadly speaking, the main point of this argument concerns a possible inaccuracy in reporting time. The participants were supposed to observe lights switching on the clock and using this as a reference, determine when the intention to act occurred. Despite the fact that the lights went on in equal time intervals and after each time the dial had been circled, the participant reported the results and the experiment was reset, there still can be doubt with regards to the precision with which the occurrence of intention was timed. Firstly, the participants had to focus simultaneously on the feeling of intention and the position on the clock. Secondly, they had to remember the position of the light.

According to Schlosser, such objections are not convincing in the view of newer experiments. For example the experiments by Klein, Haynes and Soon allow more precise and methodologically sound timing of intention. As Schlosser states, the results of these experiments contributed greatly to the overall acceptance of Libet's achievements as confirmed empirical facts ${ }^{21}$.

The work of Lau serves a similar purpose. This researcher slightly altered the way in which intention time is measured, and yet his results are comparable to that of Libet. The intention occurrence time was determined to be slightly more

\footnotetext{
${ }^{21} \mathrm{~S}$. Klein, Libet's timing of mental events: Commentary on the commentaries, "Consciousness and Cognition", 11, 2002, p. 326-333; C.S. Soon, J.D. Haynes et al., Unconscious determinants of free decisions in the human brain, "Nature Neuroscience" 11, 2008, p. 543-545, after: M.E. Schlosser, Free will and ..., op.cit., p. 367.
} 
than $200 \mathrm{~ms}$ before the movement. He also showed that as early as 2-3 seconds before, the pre-SMA (pre-supplementary motor area) is activated ${ }^{22}$.

Up until now, we have mainly discussed the problem of determining the time of intention occurrence. It can be assumed that the improved measurement methods of the time, W, confirm the fact that intention is preceded by brain activity and determine the approximate timing of this precedence.

The stability of determining the precedence of brain activity over intention is, however, yet another issue and Haynes experiment shows that this cannot be as easily confirmed.

\section{The question of determining the causal relation}

Haynes, as the result of his experiments, reached the conclusion that the stability of brain activity precedence is observed $60 \%$ of the time ${ }^{23}$. Establishing stability for the temporal precedence of brain function activation and conscious intention, would allow determining of the causal relation between the brain actions and the occurrence of intention. Hume's requirements for precedence and the stability of said precedence are assumed in establishing such a relation. Haynes experiment shows that there is some, at least statistical, problem with confirming this stability. Assuming that the $40 \%$ margin where no precedence took place is not an error in Haynes experiment and is important in establishing the lack of constant correlation, then under the falsification principle, this would serve to undermine the thesis about the causal relation.

On the other hand, the mentioned research and the Wegner experiment do support the conclusion that the Hume's requirements for intention (consciousness) to be preceded by neuronal activity had been met. These confirm not only the temporal precedence but also support the thesis about the stability of such precedence. This evidence strongly suggests the existence of a causal relation.

The importance of this problem is witnessed by the radical character of conclusions reached by certain researchers. Wegner, assuming the causal relation as given, suggests a way in which the illusion of causality works in humans: „The will is an impression, caused by an attention paid to the activation of premotor cortex (pre-SMA) ${ }^{24}$. Churchland approaches the problem of our consciousness in a similar vein. Arguing with Nagel against reductionism, Churchland points to

${ }^{22}$ H.C. Lau et al., Attention to intention, "Science" 303, 2004, p. 1208-1210, after: S. Pockett, The Neuroscience of movement, op.cit., p. 17-18.

${ }^{23}$ J.-D. Haynes, Beyond Libet: Long-Term Prediction of Free Choices from Neuroimaging Signals, Research and Perspectives in Neurosciences, Berlin - Heidelberg 2011, p. 171.

${ }^{24}$ Duch, presentation [PPT] Kognitywną Rewolucję! - Uniwersytet Mikołaja Kopernika www.is.umk.pl/ duch/ref/PL/Wola/09-automatyzmy-Krakow.ppt, [dostęp 10.11.2012] 
the proprioceptive pathways as those allowing us to notice the states of our own body, thus creating self-awareness ${ }^{25}$. Questioning the stability of precedence, and consequently the causal relation, would undermine the basis of such radical theses.

\section{The problem of reversibility of requests}

The problem which we have called the 'problem of reversibility of requests' is related to the extent to which intentions of a conscious individual, that one has influenced at some point in the past, can be analysed. Lau and Passingham emphasise the problematic character of the consciousness studies, where conscious patients are subject to requests influencing their consciousness, which is then analysed. For example, the time of a given action and its content are suggested by previous instructions describing what and when should be performed during the studies ${ }^{26}$. The salient point is that when the participant is given an instruction beforehand, stating that a certain movement should be performed, and their consciousness of movement initiation is observed; there is no certainty if the participant did not have such an intention moments after familiarising with the instructions. Hence what is later reported as the intention of making a movement could well be a derivative of this initial instruction. This in turn would contradict the temporal precedence of brain activity over conscious intention. Hence, the established causal relation between brain actions and intentions would be called into question.

The problem of reversibility of requests was tackled in a broader context by Mele.

\section{Critique of the conlusions}

A. The understanding of intention

According to Mele, Libet interchangeably uses words such as: 'decision', 'intention', 'want', 'wish', 'desire'. Hence, there is a problem of ambiguity. Mele claims that most people do notice a difference between wanting to do something and decision of doing it:

${ }^{25}$ P.M. Churchland, Mechanizm rozumu, siedlisko duszy. Filozoficzna podróż w głąb mózgu, translated by Z. Karaś, Warszawa 2002, p. 216-221; T. Nagel, Jak to jest być nietoperzem?, in: idem, Pytania ostateczne, translated by A. Romaniuk, Warszawa 1997. For the so-called Nagel bat problem see: P. Strzyżyński, Problem ,nietoperza Nagel'a” w argumentacji Johna Hicka i Paula M. Churchlanda, "Filozofia Chrześcijańska" vol. 7, 2010, p. 65-71.

${ }^{26}$ H.C. Lau, R.D. Rogers, P. Haggard, R.E. Passingham, Attention to intention, after: S. Pockett, The Neuroscience of movement, op.cit., p. 19. 
[...] you might want to have a second helping of dessert but decide to stop at one. If, as I believe, to decide to $A$ is to perform a momentary mental action of forming an intention to $A[\ldots]$, then in deciding to stop at one dessert you form an intention to stop at one. Your having that intention also differs from your merely wanting to stop at one dessert. You might want to have another dessert (it is very tempting) while also wanting to refrain from having it (you are concerned about your weight); but intending to have a second helping of dessert while intending to refrain from doing that, if it is possible at all, would be a sign of a serious disorder ${ }^{27}$.

According to Mele, "if Libet himself were to distinguish between intending and wanting (including having an urge)[...], he might find it more credible to associate the readiness potentials with the latter [urge, desire - P.S.] than with the former [intentions - P.S.]" ${ }^{28}$. Such a distinction would prove useful in describing the phenomenon of veto. Mele, criticising the idea of veto, claims that it is not possible to simultaneously intend to make a move and to stop it. In Libet's experiment, veto functions as the result of intention of blocking a move that had been previously intentionally planned. However, if Libet had accepted the distinction proposed by Mele, it would have significantly weakened the impact of his experiment, since it is not as controversial to state that needs and desires can be generated by the brain as it is to claim the same for intentions, which are often associated with the free will. We point out that Mele defends this approach against the assumption that the free will has to have the power to initiate actions. Whereas, in Libet's interpretation will does not initiate but at most prohibits actions. Despite the fact that Libet rejected Mele's distinctions as having been made ad hoc, there were more positive reactions to the distinctions posited by Mele ${ }^{29}$. On the other hand, according to Pockett these do not change the general implication of Libet's experiment that brain activity precedes intentions and movement and that whatever the exact nature of these neuronal activities, they precede consciousness $^{30}$. It is hard, however, to accept Pockett's interpretation without first agreeing if Mele's arguments are misinformed. Since, if we accept Mele's reservations as justifiable, we conclude that intentions occur even before the experiment has started, hence before the recorded brain activity. If this is the case, what was interpreted as the intention of making the move could have merely been an awareness of activation of this primary intention.

Deecke and Kornhuber take similar approach. On the basis of the experiments, they suggest that: prior to the experiment, a general decision on making periodic movements is made; it is then possible that the decision regarding spe-

${ }^{27}$ A.R. Mele, Free will: Theories, analysis, and data, in: Does consciousness ..., op.cit., Cambridge 2006, p. 190.

${ }^{28}$ Ibidem, p. 192.

${ }^{29}$ M.E. Schlosser, Free will and ..., op.cit., p. 369.

${ }^{30}$ S. Pockett, The Neuroscience of movement..., op.cit., p. 18. 
cific individual movements is sub-conscious and that consciousness is switched on about $200 \mathrm{~ms}$ prior to the movement; this $200 \mathrm{~ms}$ interval gives time to veto the movement ${ }^{31}$.

Hence, the conceptual ideas of Mele are not incompatible with the results of experiments similar to those conducted by Libet. Moreover, these support the principle of saving the phenomena even more than the deterministic interpretation $^{32}$. This principle speaks against hastened rejection of data coming from everyday experience, if, obviously, the scientific or philosophical explanation does not unequivocally show the contrary to which the everyday experience points. Out of two interpretations of Libet's experiment: deterministic and the one proposed by Mele, the latter allows one to retain the common-sense belief with regards to the causal character of free will and the possibility of consciously exercised influence on actions. Even in Libet's conclusions, as quoted above, one notices an attempt at saving the phenomena. Namely, quoting its inconsistency with our internal experience, Libet rejects the deterministic hypothesis.

\section{B. Interpretation of RP}

The key role in the interpretation of Libet's experiment is played by the meaning given to the readiness potentials (RP). The deterministic interpretation is supported by the assumption of a strong and direct correlation between physical movements with preceding RP discharges them. There are, however, studies indicating a more complex nature of the correlation between RP and movements. On the basis of the reviewed literature and their own research Shibasaki and Hallett conclude that

Automatic movements such as eyelid blinks, spontaneous eye movements, chewing, swallowing, and respiration also controlled by volitional factors to a certain degree. Thus, BP is recorded when these movements are repeated at a self-paced rate. However, it is not known whether these movements when occurring under automatic and more natural conditions are associated with BP or not ${ }^{33}$.

On the other hand, RP occurs in the case of saccadic movements, yet it is virtually absent in patients with degenerative diseases such as progressive myoclonic ataxia. According to these authors ,typical complex of early BP and late

\footnotetext{
${ }^{31}$ L. Deecke, H.H. Kornhuber, Human freedom, reasoned will, and the brain: The Bereitschaftspotential story, in: The Bereitschaftspotential. Movement-related cortical potentials, ed. M. Jahanshahi, M. Hallett, New York 2003, p. 283-320, after: H. Shibasaki, M. Hallett, What is the Bereitschaftspotential?, "Clinical Neurophysiology", 117, 2006, p. 2353.

32 J. Baggini, P.S. Fosl, The Philosopher's Toolkit. A Compendium of Philosophical Concepts and Methods, Oxford 2003, p. 122-124.

${ }^{33}$ H. Shibasaki, M. Hallett, What is the Bereitschaftspotential?..., op.cit., p. 2347.
} 
$\mathrm{BP}$ is never recorded before organic involuntary movements, the demonstration of early BP and late BP before the movement in question strongly suggests its psychogenic origin, and we use this routinely in clinical practice" 34 . According to the researchers, the magnitude of RP discharges depends on the intention, motivation, effort and other characteristics of the movement, resulting in large differences in the output of an experiment. Moreover, early RP might be related to a subconscious preparation for the future move, whereas late RP might be related to the conscious will of making a move ${ }^{35}$. Generalising the above, RP occurs prior to movements linked to a conscious decision, related to their execution and do not occur prior to involuntary movements. A question suggests itself at this point regarding the meaning of the absence of RP in involuntary movements, for the interpretation of RP occurrence in the case of voluntary movements.

We should like to observe that the consciousness is correlated not only with the voluntary - but also involuntary - movements. For it is quite possible that one can sense and is aware of (where this consciousness comes from observation; we hereinafter refer to it as observational consciousness) breathing or blinking. This consciousness can be interpreted as a derivate of the functions played by the, mentioned by Churchland, proprioceptive pathways. Observational consciousness of a similar type can be observed in case of voluntary movements. According to Shibasaki and Hallet, the readiness potentials are correlated with the latter type of movements. It can be stipulated that these movements are somehow characteristic enough to activate specific brain regions, which is detected as RP. The question arises then, what is this characteristic feature, setting apart the voluntary movements from the involuntary ones. Observational consciousness itself cannot be considered to play this role on its own, since it is present in both types of movement. If one assumes that the intention of making a movement is this feature, then perhaps RPs are derivatives of a process, where this intention intervenes in the physicochemical process occurring in the brain. If there were no other possible causes related to the RP occurrence in voluntary movements, intention would be an important step toward the solution of this conundrum. This does not mean however that intention is independent of the physicochemical activity of the brain. Perhaps, as a result of evolution, a mechanism took shape, requiring that complex movements (and many voluntary movements are complex) have a more precise set of actions, activation of which is correlated to the activation of the motor cortex, and which is measured as RP. At the same time, this more complex process results in consciousness, not only observational but a causal one, which is then interpreted as intention. Yet another explanation is

\footnotetext{
${ }^{34}$ Ibidem, p. 2352.

${ }^{35}$ Ibidem, p. 2351-2353.
} 
also possible; here intention is not related to RP as cause but as a process occurring separately but in parallel; or as a cause of brain activation.

In the Hermann group experiment, the participants were asked to either make a move with a chosen arm or to refrain from making the move, after a specific signal. The results contradict the stronger interpretation of Libet's experiment. The stronger interpretation states that will is determined by the neuronal processes. According to the authors

Because the RP sets in before the stimulus is presented and participants react appropriately, the RP cannot determine which of two alternatives available (righthand vs. left-hand movement) is executed. Rather, the RP seems to reflect a general expectation or an unspecific motor preparation of both hands. [...] It would seem, then, that there are reasons to reject the stronger hypothesis and to doubt whether Libet's results can be interpreted as evidence against the freedom of will ${ }^{36}$.

At this point, it seems worthwhile to take a closer look at the interpretation of the fact that RP discharges precede movements. Since the movement is not defined in its quality (that is, what there is to be done is not specified), and each such decision is accompanied by intention, RP cannot be a source of a specific intention to make a movement with a specific arm. If the research held its own against the critique, it would rather support the hypothesis - out of the two outlined in the previous paragraph - that does not interpret intention as the effect of the neuronal processes recorded as RP.

One conjectures that the replacement of EEG as the research method with a more accurate technology will help solving this problem. In their research, Soon and colleagues instead of EEG used fMRI (functional magnetic resonance imaging) as their method of choice. The participants had to choose not only the time of pressing a button but also the hand to use to do this. This allowed an analysis of decisions regarding not only ,when” but also ,what” (the choice of action and the choice of the hand to be moved). After the research, the authors concluded that „Brain activity that is predictive of what-decisions was found as early as $10 \mathrm{~s}$ before the conscious choices, and brain activity that is predictive of when-decisions was found as early as $5 \mathrm{~s}$ before the conscious choices" ${ }^{\prime 37}$. Hence, another brain activity imaging method confirms the temporal precedence of neuronal processes with regards to intention. Moreover, even the what-decision is being preceded by the activation of relevant brain areas. Hence, it seems that this experiment does support the deterministic explanation of intention as derivative of

\footnotetext{
${ }^{36}$ Ch.S. Herrmann et al., Analysis of choice-reaction task yield a new interpretation of Libet's experiments, "International Journal of Psychophysiology", 67, 2008, p. 156.

${ }^{37}$ J.D. Haynes et al., Unconscious determinants of free decisions in the human brain, "Nature Neuroscience", 11, 2008, p. 543-545, after: M.E. Schlosser, Free will and ..., p. 371.
} 
neuronal processes. On the other hand, the experiment results, as described above - despite the fact that the neuronal activity and RP occurred prior to the movement and the decision with regards to the particular hand being moved - were not interpreted as the cause of intention, but as a generalised readiness for making a move.

\section{The problem of generalisation from simple actions to complex ones}

One of the arguments against Libet's experiment and his interpretation is that Libet commits a hasty generalisation fallacy. From simple hand movements he extrapolates the precedence of neuronal activity with regards to all types of movements, and even decisions. As a result, he is able to draw a general conclusion that conscious intentions are preceded by neuronal activity. Zhu, for example, claims that Libet's experiment deals only with distant intentions and not with the direct ones. Zhu notes that at the beginning of the experiment, the participants had already known what they are supposed to do. Moreover, Libet asked them to make a move in a specific time interval ${ }^{38}$.

Schlosser on the other hand states that the participants only made the decisions of ,when" to make a move and not ,what" there is to be done. Whereas the latter are far more important: „when” is secondary to „what”.

Yet, the experiment of Haggard and Eimer, where participants were asked to choose when and with which hand to make a move, are comparable in terms of results to that of Libet ${ }^{39}$.

Libet himself argues that his results can be generalised to all the planned and spontaneous actions. He states that in the experiments where participants reported previous planning of making a move, the RP precedence was comparable to the situation where decisions were made spontaneously. Moreover, other researchers showed that RP was detected even in the cases of some more complex activities such as reading or writing ${ }^{40}$.

The thesis about partial generalisation of Libet's experiment is also supported by the aforementioned experiment by Soon. Here, the participants had to choose not only the time of pressing a button but also the hand they used to do this. This allowed investigation of not only the ,when" decisions but also ,what" decisions ${ }^{41}$.

${ }^{38} \mathrm{~J}$. Zhu, Reclaiming volition: An alternative interpretation of Libet's experiment, "Journal of Consciousness Studies", 10, 2003, p. 61-77, after: M.E. Schlosser, Free will and ..., op.cit., p. 369.

${ }^{39} \mathrm{P}$. Haggard, M. Eimer, On the relation between brain potentials and the awareness of voluntary movements, "Experimental Brain Research", 126, 1999, pp. 128-133, after: M.E. Schlosser, Free will and ..., op.cit., p. 372.

${ }^{40}$ B. Libet, Do we have free will?, ..., op.cit., p. 560.

${ }^{41}$ J.D. Haynes et al., Unconscious determinants ..., op.cit., after: M.E. Schlosser, Free will and ..., op.cit., p. 371. 
Hence, one is justified in assuming that neuronal processes precede certain movement and decisions of more complex nature than just the „when” decisions. Moreover, the research made by Hayens suggests that the brain activates earlier than the conscious decision - with regards to adding or subtracting numbers occurs $^{42}$.

This research suggests that even very complex mental processes are preceded by neuronal activity. Hence, the generalisation made by Libet should be deemed justified.

Moreover, Pockett observes that consciousness might be absent - also as a causative factor - from certain complex movements altogether ${ }^{43}$. What he means here, are the very fast corrective movements, which - if made consciously would be too slow to be effective. For example, an immediate correction of car route in case of possible collision course would be impossible, if it were to be a result of a conscious analysis of the situation and making the decision.

We should point out however that the movements Pockett deals with include automatic motor responses. Such movements are a result of training or reflex reaction. Consciousness of the decision would, in such cases, impede its execution; however this does not contradict the assumption that consciousness could have played a very important role in the training of such movements, namely the role of controlling the process of reflex reaction training.

\section{The problem with "veto control”}

The possibility of refraining from executing a decision, dubbed by Libet as „veto control" has some serious implication on the interpretation of his experiment. According to Schlosser, Libet:

$[\ldots]$ thought that the experimental results are incompatible with the philosophical and common sense conception, according to which free will requires the power to initiate actions consciously. But the results are compatible with a more modest conception, according to which free will consists in the ability to consciously control by way of vetoing - we don't have free will, but we have free won' $t^{44}$.

Moreover, the author suggests that since Libet observes „,veto control”, he cannot be talking about determinism, since determinism rejects the possibility of stopping a movement ${ }^{45}$. He also notes that the experiments aimed at improving

\footnotetext{
${ }^{42}$ W. Duch, presentation [PPT] Kognitywną Rewolucję! - Uniwersytet Mikołaja Kopernika www.is.umk.pl/ duch/ref/PL/Wola/09-automatyzmy-Krakow.ppt, [10.11.2012].

${ }^{43}$ S. Pockett, The Neuroscience of movement..., op.cit., p. 20-21.

${ }^{44}$ M.E. Schlosser, Free will and the unconscious..., op.cit., p. 367.

${ }^{45}$ Ibidem, p. 370.
} 
Libet's results and supporting his conclusions, assume a rather traditional notion of a free will as possessing the power to initiate an action, and not only the power to stop an action. His suggestion is then to accept the compatibilist approach. According to this approach, free will can be present when one is not forced to act, has a choice, but not the power to initiate the act. Such conceived free will is not affected by Libet-style experiments ${ }^{46}$.

Mele, as it has been mentioned, attempts to emphasise the problems related to the „veto" intention. The participants of Libet's experiments were supposed to want to make a movement and plan to refrain from it. These two attitudes are mutually exclusive. Mele states that: , [...] it is very plausible that Libet is mistaken in describing what is vetoed as «intended motor action»" ${ }^{47}$. Pocket, Banks and Gallagher are also critical when it comes to the interpretation of veto ${ }^{48}$.

If Mele is right, then Libet's interpretation has to overcome the difficulty related to showing that it is possible to hold two mutually exclusive intentions simultaneously. Mele's objections could be tackled by designing an experiment, where the participants are suggested to refrain from movement right before its execution and where results similar to Libet's are obtained. The difficulty related to such an experiment lies in the fact that the time interval between making the decision and possibility of changing it is very short and approximately equals 200ms. The difficulties related to designing and implementing Libet-style experiments and the problems inherent to interpreting the role of consciousness are best described by Pockett, when talking about the more complex decisions or longterm intentions: „However, while it is clear that consciousness is generally associated with these processes, nobody has yet been able to design experiments that would unequivocally nail down the temporal relationship between the appearance of this consciousness and the onset of whatever neural events underpin the intentions and movement-initiations" ${ }^{\prime 4}$.

\section{THE CONSCIOUS MENTAL FIELD THEORY}

During the - lasting for years - free will debate, Libet in 1994 put forward the so-called conscious field theory (CMF), which was an interesting, yet surprising contribution ${ }^{50}$. It posits an existence of some non-measurable, but origi-

\footnotetext{
${ }^{46}$ Ibidem, p. 366.

${ }^{47}$ A.R. Mele, Free will: Theories ..., op.cit., p. 193.

${ }^{48}$ S. Pockett, W.P. Banks, S. Gallagher (ed.), Does consciousness..., op.cit., p. 2.

${ }^{49}$ S. Pockett, The Neuroscience of movement..., op.cit., p. 22.

${ }^{50} \mathrm{~B}$. Libet, A testable field theory of mind-brain interaction, "Journal of Consciousness Studies" Vol. 1(1), 1994, p. 119-126.
} 
nating in brain, mental quality. Libet also designed the experiment to verify this theory. It consists in separating the sensory cortex from the rest of the brain in such a way, so that all the nerve connections are severed but the blood supply is intact. According to Libet: „The prediction is that electrical stimulation of the sensory slab will produce a subjective response reportable by the subject. That is, activity in the isolated slab can contribute by producing its own portion of the $\mathrm{CMF}^{\prime \prime}$. If such field was created, it would mean that between the isolated piece and the rest of the brain there is some relation of a non-neuronal character. Such relation would be, according to Libet, a new quality escaping the realm of physical tests:

The CMF is [...] a system produced by billions of nerve cell actions, it can have properties not directly predictable from these neuronal activities. It is a non-physical phenomenon, like the subjective experience that it represents. The process by which the CMF arises from its contributing elements is not describable. It must simply be regarded as a new fundamental «given» phenomenon in nature, which is different from other fundamental "givens" like gravity or electromagnetism ${ }^{52}$.

The mental field would originate in the brain but would be also able to influence it. This would mean a strengthening of antireductionism to some extent, a position arguing against total identification of mind and brain. The conscious mental field theory would also explain the phenomenon of the perceived unity of conscious perceptions. Since, it is hard to reconcile the unity of one's own consciousness with its origin from many isolated neuronal discharges. According to Libet, „The CMF would unify the experience generated by the many neural units. It would also be able to affect certain neural activities and form a basis for conscious will" 53 . Apparently then, this theory could be also considered an argument for the existence of conscious free will. Proving the existence of a field of extraphysical interactions that was related to brain and that influenced the conscious experiences and even the actions of brain itself, would allow the conclusion that there exists a will that is independent from these actions, hence a free one. Libet warns however that "the conscious mental field theory [...] is not dualism, in the Cartesian sense; the CMF does not exist without the living brain, and is an emergent property that brain" 54 . Libet's theory has the valuable feature of being testable. The procedure of verifying it would consist in performing the abovementioned experiment. In 2003, four years before his death, Libet wrote that he hopes that

${ }^{51}$ B. Libet, Reflections on the Interaction of the Mind and Brain, "Progress in Neurobiology" 78, 2006, p. 324 .

${ }^{52}$ Ibidem.

${ }^{53}$ B. Libet, Can Conscious Experience Affect Brain Activity, "Journal of Consciousness Studies", Vol. 10, 2003, p. 27.

${ }^{54}$ Ibidem, p. 28. 
scientists would one day be able to perform such an experiment ${ }^{55}$. It has been twenty years since Libet first time proposed his theory, which may indicate that such an experiment is indeed very difficult to implement.

\section{FINAL REMARKS}

The above reconstruction of the current state of affairs in terms of discussion surrounding Libet's experiment yields a number of conclusions.

Firstly, against some of the interpretations, Libet does not endorse determinism and does not state that free will has no impact on our actions. He does limit this impact however, denying the role of free will in the initiation phase and seeing its main role in refraining from actions. This understanding of free will is consistent with compatibilism rather than indeterminism or incompatibilism.

Secondly, the notion of will endorsed by Libet can influence the understanding of moral responsibility. It is not, however, a radically new approach, for it is based on the assumption that one cannot be punished or rewarded for involuntary actions. Libet's contribution is to extend the scope of these actions to, for example certain types of thoughts, wishes or desires. But in his, admittedly cursory, description the thoughts, desires or urges occurring spontaneously are no different to those that also occurred spontaneously but their existence (feeling, thinking) is consciously extended or that did not occur spontaneously but were consciously created. The problem of moral responsibility for mental actions of this kind would disappear if one managed to show that man has no real influence on any type of his or her mental states, which seems to be very challenging indeed.

Thirdly, Libet's interpretation is based on a number of assumptions. One of them is that RP always precedes movements and occurrences of intentions. As it has been shown, this precedence was not always shown. Whereas, the very fact of this precedence can indicate that the general intention of making a move is a result of previous mental attitude. In most cases, RP occurs before the voluntary movements, which suggests their mental, and not only brain, origin.

Another assumption is related to the interpretation of RP as coming from the motor regions of the brain. The RP origin is also not completely certain and if RP can be generated in deeper brain structures, and if confirmed, it would weaken their interpretation as the indicators of activation are just the motor cortex.

Yet another assumption is related to generalisation of the results. It seems that there is enough evidence supporting generalisation of RP precedence to all physical movements. However, generalisation to more complex decisions is currently

\footnotetext{
${ }^{55}$ Ibidem.
} 
under investigation. We emphasise that such a generalisation with regards to precedence and constant precedence would be justifiable only when all the mentioned objections against the proposed interpretation of RP are also tackled.

Fourthly, the differentiation between desires, wishes and intentions or even between direct and indirect intentions proposed by Mele, seems justifiable. By accepting it, we are preserving the notion that man is a subject initiating actions and not only able to refrain from actions. Also, it is consistent with the research interpreting RP as an indicator of general readiness to action has having mental origin. Hence, it seems justifiable to postulate clarification of notions during the design and subsequent description of experiments of the type initiated by Libet.

A separate assumption is related to identifying intention with the feeling of intention. It is conceivable to have intentions that, notwithstanding being the results of previous conscious actions, to a certain moment in time remain unconscious. Hence, the influence of unconsciousness and consciousness would have to be somehow eliminated from the Libet-type experiments.

Objections raised in relation to the methodology, interpretation and certain theoretical assumptions behind the experiment, suggest that the conclusion about biophysical determination of will and consciousness by specific brain processes is still premature.

Even the conscious mental filed theory, although interesting, is important only theoretically and not as an argument in the free will debate.

\section{BIBLIOGRAPHY}

Baggini J., Fosl P.S., The Philosopher's Toolkit. A Compendium of Philosophical Concepts and Methods, Oxford 2003.

Bremer J., Wprowadzenie do filozofii umystu, Kraków 2010.

Churchland P.M., Mechanizm rozumu, siedlisko duszy. Filozoficzna podróż w głab mózgu, translated by Z. Karaś, Warszawa 2002.

Deecke L., Kornhuber H.H., Human freedom, reasoned will, and the brain: The Bereitschaftspotential story, in: The Bereitschaftspotential. Movement-related cortical potentials, ed. M. Jahanshahi, M. Hallett, New York 2003, 283-320.

Domańska Ł., Borkowska A.R. (ed.), Podstawy neuropsychologii klinicznej, Lublin 2008.

Duch W., presentation [PPT] Kognitywna Rewolucję! - Uniwersytet Mikołaja Kopernika, www.is.umk.pl/ duch/ref/PL/Wola/09-automatyzmy-Krakow.ppt, [dostęp 10.11.2012].

Fix J.D., Neuroanatomia, ed. J. Moryś, Wrocław 1997, pp. 367.

Górska T. i in., Mózg a zachowanie, PWN, Warszawa 2011.

Haggard P., Eimer M., On the relation between brain potentials and the awareness of voluntary movements, "Experimental Brain Research" 126, 1999, p. 128-133. 
Haynes J.D., Beyond Libet: Long-Term Prediction of Free Choices from Neuroimaging Signals, Research and Perspectives in Neurosciences, Berlin-Heidelberg 2011, p. 161-174 .

Haynes J.D. et al., Unconscious determinants of free decisions in the human brain, "Nature Neuroscience" 11, 2008, p. 543-545.

Herrmann Ch.S. et al., Analysis of choice-reaction task yield a new interpretation of Libet's experiments, "International Journal of Psychophysiology" 67, 2008, p. 151-157.

Jahanshahi M., Hallett M. (ed.), The Bereitschaftspotential. Movement-related cortical potentials, New York 2003.

Kane R. (ed.), Oxford handbook of free will, New York 2002.

Kane R. (ed), Oxford handbook of free will, New York 2011.

Klein S., Libet's timing of mental events: Commentary on the commentaries, "Consciousness and Cognition" 11, 2002, p. 326-333.

Lau H.C. et al., Attention to intention, "Science" 303, 2004, p. 1208-1210.

Libet B., A testable field theory of mind-brain interaction, "Journal of Consciousness Studies" vol. 1(1), 1994, p. 119-128.

Libet B., Can Conscious Experience Affect Brain Activity, "Journal of Consciousness Studies" vol. 10, 2003, p. 24-28.

Libet B., Consciousness, free action and the brain, "Journal of Consciousness Studies" no. 8, 2001, p. 59-65.

Libet B., Do we have free will?, in: Oxford handbook of free will, ed. R. Kane, New York 2002, p. 551-564.

Libet B., Reflections on the Interaction of the Mind and Brain", "Progress in Neurobiology" vol. 78 (3-5), 2006, p. 322-326.

Libet B., Unconscious cerebral initiative and the role of conscious will in voluntary action, "Behavioral and Brain Science" 8, 1985, p. 529-539.

Mele A.R., Free will: Theories, analysis, and data, in: Does conscious cause behavior?, ed. S. Pockett, W.P. Banks, S. Gallagher, Cambridge 2006, p. 187-206.

Nagel T., Jak to jest być nietoperzem?, in: idem, Pytania ostateczne, tłum. A. Romaniuk, Warszawa 1997, p. 203-219.

Pockett S., Banks W.P., Gallagher S., Introduction, in: Does conscious cause behavior?, ed. S. Pockett, W.P. Banks, S. Gallagher, Cambridge 2006.

Pockett S., Banks W.P., Gallagher S. (ed.), Does conscious cause behavior?, Cambridge 2006.

Pockett S., The Neuroscience of movement, in: Does conscious cause behavior?, ed. S. Pockett, W.P. Banks, S. Gallagher, Cambridge 2006, p. 9-24.

Quigg M., EEG w praktyce klinicznej, red. J. Jędrzejczak, Wrocław 2008.

Rektor I., Scalp-recorded Bereitschaftspotential is the result of the activity of cortical and subcortical generators - a hypothesis, "Clinical Neurophysiology” 113, 2002, p. 1998-2005 . 
Satow T. et al., Distinct cortical areas for motor preparation and execution in human identified by Bereitschaftspotential recording and EcoG-EMG coherence analysis, "Clinical Neurophysiology" 114, 2003, p. 1259-1264.

Schlosser M.E., Free will and the unconscious precursors of choice, "Philosophical Psychology" vol. 25, no. 3, 2012, p. 365-384.

Strzyżyński P., Problem ,nietoperza Nagela” w argumentacji Johna Hicka i Paula M. Churchlanda, "Filozofia Chrześcijańska" vol. 7, 2010, p. 65-71.

Thompson M., Thompson L., Neurofeedback - wprowadzenie do podstawowych koncepcji $i$ psychofizjologii stosowanej, red. I. Wolska-Kontewicz i in., Wrocław 2012 $\left[2003^{1}\right]$.

www.rupertsheldrake.wordrpess.com [dostęp 07.01.2013].

Zhu J., Reclaiming volition: An alternative interpretation of Libet's experiment, "Journal of Consciousness Studies"10, 2003, pp. 61-77.

\section{SUMMARY}

The article describes the results of Libet's experiment and its resulting critique, as witnessed by the articles published between 2000 and 2012. As a result of his experiments, Libet concluded that conscious intentions of making a movement are preceded by brain activity registered as the readiness potentials (RP). In this interpretation, free will does not initiate the decision of making a move but is however capable of stopping this process. For this reason, Libet does not conclude that will is determined by biological processes. The resulting discussion in the literature concerns mainly methodology and conclusions drawn by Libet. The methodological points raised include an argument against the use of EEG as an accurate research tool and criticism of the method of timing the occurrence of the conscious intention of making a move. We note that subsequent modifications made to the original experiment, did however allow putting some of the methodological doubts to rest. On the other hand, the critique of Libet's conclusions focuses on the problematic nature of correlation of physical movements with the readiness potentials. The most recent research also shows that the potentials might have a more complicated origin than previously thought. Libet's interpretation is also criticised for its vagueness in defining intention and for not distinguishing it from wishes and desires. The last part of our article summarises the latest state of affairs as emerging from the analysis. We point out the difficulties in correlating potentials with movement, their interpretation and difficulties with the notion of veto, since it seems to require that contradictory intentions of making and refraining from a movement are present simultaneously. The article concludes that on the basis of the current research, the thesis about a biological determination of voluntary processes lacks a sound justification.

\section{Keywords}

Libet experiment, free will, readiness potentials (RP), veto control, free will as a veto, intentions, causality

\section{Słowa kluczowe}

eksperyment Libeta, wolna wola, potencjały gotowości, kontrola veto, wolna wola jako kontrola vet, intencje, przyczynowość 